\title{
Vertical Phosphorus Migration in a Biosolids-Amended Sandy Loam Soil in Laboratory Settings: Concentrations in Soils and Leachates
}

\author{
Yulia Markunas, ${ }^{1}$ Vadim Bostan, ${ }^{1}$ Andrew Laursen, ${ }^{1}$ Michael Payne, ${ }^{2}$ and Lynda McCarthy \\ ${ }^{1}$ Department of Chemistry and Biology, Ryerson University, 350 Victoria Street, Toronto, ON, Canada M5B 2K3 \\ ${ }^{2}$ Black Lake Environmental, 246 Black Lake Route, Perth, ON, Canada K7H 3C5
}

Correspondence should be addressed to Vadim Bostan; vbostan@ryerson.ca

Received 24 May 2016; Revised 5 October 2016; Accepted 16 October 2016

Academic Editor: Rafael Clemente

Copyright (C) 2016 Yulia Markunas et al. This is an open access article distributed under the Creative Commons Attribution License, which permits unrestricted use, distribution, and reproduction in any medium, provided the original work is properly cited.

\begin{abstract}
The impacts of biosolids land application on soil phosphorus and subsequent vertical migration to tile drainage were assessed in a laboratory setup. Soil, representing typical "nonresponse" Ontario soil as specified by Ontario Ministry of Agriculture, Food, and Rural Affairs (OMAFRA), was amended with anaerobically digested biosolids at a rate of $8 \mathrm{Mg} \mathrm{ha}^{-1}$ (dry weight). Over five months, these amended soil samples from two different depths were sequentially fractionated to determine various inorganic and organic phosphorus pools in order to evaluate phosphorus vertical migration within a soil profile. Soil leachate was analyzed for soluble reactive phosphorus. The results indicated that biosolids application did not significantly affect phosphorus concentrations in soil and did not cause phosphorus vertical migration. The concentrations of soluble reactive phosphorus also were not significantly affected by biosolids.
\end{abstract}

\section{Introduction}

Even though the term biosolids, as it is understood now, only appeared at the end of 20th century, the concept of human waste application to agricultural lands has been known for thousands of years [1]. Agricultural land application is considered a viable way to recycle municipal biosolids. Biosolids are valued as a soil conditioner [1] and as a source of macro- and micronutrients and organic matter necessary for healthy crops $[2,3]$.

Even though municipalities, farmers, and the general public may benefit from the use of biosolids on agricultural lands, there are some environmental concerns related to this practice. One of these concerns is the relatively high level of total phosphorus in biosolids and its potential migration to surface- and groundwater from biosolids-amended lands [4] as its overabundance in surface water can lead to eutrophication [5]. Many wastewater treatment plants (WWTPs) use alum or $\mathrm{FeCl}_{3}$ in tertiary treatment to precipitate phosphorus, which becomes part of the biosolids material. Further, stabilization of raw sewage or biosolids by alkaline stabilization may result in some phosphorus precipitation as $\mathrm{Ca}_{3}\left(\mathrm{PO}_{4}\right)_{2}$. As a result the phosphorus may be in forms that are not biologically available, or in forms that retard migration from point of application [6]. Therefore, total phosphorus in biosolids may not be relevant in considering the risk posed by phosphorus loss from fields to aquatic systems. Rather, to properly assess potential risk of biosolids-derived phosphorus to receiving waters, it may be more important to consider the various fractions of phosphorus in biosolids and their behaviour in soil (e.g., migration and transformation).

Generally, phosphorus has the potential of being transported to aquatic systems through three major pathways: surface runoff and erosion, subsurface flow, and tile drainage $[4,7]$. To a smaller extent, it can also be transported by wind erosion and deposition [8]. Runoff and erosion are important pathways of soil phosphorus loss $[9,10]$, and the majority of studies on phosphorus loss from agricultural land 
are devoted to losses through runoff and erosion [11-16]. Application of municipal biosolids, specifically, can increase total phosphorus (TP) in runoff from soil in laboratory mesocosms [17], although loss of $\mathrm{P}$ in runoff in agricultural soils may be dependent on the stabilization method used to produce the biosolids [18-20]. These losses represent only horizontal migration of phosphorus through surface runoff, while vertical migration of phosphorus through the soil layers can also contribute to the phosphorus escape from agricultural lands [21]. It is especially significant in areas with little slope, areas with shallow groundwater, dry areas, or less weathered soils and organic soils that have a low phosphorussorbing capacity $[22,23]$. Vertical migration represents a potential route for phosphorus loss in agricultural areas, yet few studies have considered vertical phosphorus migration, and none were found to have considered vertical migration and evolution of the various phosphorus fractions relevant to biosolids-amended soils.

The purpose of this study was to determine, in a laboratory setting, how land application of biosolids might affect various phosphorus fractions in soil, time-related transformations among fractions, and vertical loss of phosphorus to leachate.

\section{Material and Methods}

2.1. Experimental Setup. In order to study vertical $P$ migration, a series of soil columns were constructed in the laboratory [24]. Laboratory soil columns consisted of a series of eight plastic columns ( $7 \mathrm{~cm}$ diameter, $60 \mathrm{~cm}$ height). These columns had rubber end-caps, and a plastic funnel $(7 \mathrm{~cm}$ outer diameter) was inserted into each column with the stem of the funnel protruding through a hole in the end-cap. The bottom $10 \mathrm{~cm}$ of the column (immediately above the funnel) was filled with river gravel to improve the drainage of the leachate percolating through the soil and to prevent soil from escaping through the funnel. Above the gravel, each column was filled with $40 \mathrm{~cm}$ of sandy loam soil. The soil had a bulk density of 1.4 with $3 \%$ organic matter and a $\mathrm{pH}$ of 6.5 and has a good water drainage. It is commercially available from "Circle Farms" in Brantford Ontario and it was selected as it is a good representative for the farm soils in southern Ontario. The four randomly selected columns were amended with $3.65 \mathrm{~g}$ of anaerobically digested biosolids (dry weight), equivalent to a rate of $8 \mathrm{Mg}$ (dry weight) $\mathrm{ha}^{-1}$. This was achieved by adding $260 \mathrm{~mL}$ of biosolids at $1.4 \%$ dry matter on top of the soil in each column selected for biosolids application and incorporated into the top $5 \mathrm{~cm}$. Reference columns were watered with the same volume of distilled water $(260 \mathrm{~mL})$. The biosolids used in the current research were produced at a Southern Ontario wastewater treatment plant. The sewage treatment process at this plant utilizes a conventional secondary activated sludge process with chemical phosphorus removal and anaerobic sludge digestion. Secondary treatment involves phosphorus removal via precipitation with iron (in form of ferric chloride) followed by the addition of sodium hypochlorite as a disinfectant to the treated water. Consequently, precipitated $\mathrm{FePO}_{3}$ becomes a constituent of the activated sludge and ultimately the biosolids. Anaerobic digestion of the sludge occurs in airtight reactors over a twoweek period. Biosolids produced at this wastewater treatment plant are either used on agricultural land or dewatered and landfilled. In Ontario, $8 \mathrm{Mg}$ of biosolids (dry weight) per ha of land per 5 years is the common application rate [25] and was used in other similar studies [26].

2.2. Sampling. An initial set of soil samples (before biosolids application) was collected for analysis of phosphorus fractions, including the Olsen sodium bicarbonate extractable phosphorus. Subsequent sample collections were performed with decreasing periodicity: two weeks, one month, two months, three months, and five months after biosolids application. The duration of the experiment approximated a growing season for southern Ontario. At each sampling period, approximately $2 \mathrm{~g}$ of soil samples was collected from two different depths within the soil columns $(3 \mathrm{~cm}$ from the top and $35 \mathrm{~cm}$ from the top). Due to the 1.4 bulk density of the soil, each soil sample had a volume of approximately $3 \mathrm{~cm}^{3}$. The samples were collected by drilling holes in the plastic columns, extracting one soil aliquot per each column, at each of the two depths, and subsequently sealing the holes with silicone glue. Water (approximately $200 \mathrm{~mL}$ per column) was added to columns on a weekly basis. Leachate samples were collected with decreasing periodicity: 1 day, 2 weeks, 1.5 months, 2 months, 3 months, and 5 months after biosolids application. All sampling events happened next day after water was added to the columns [24].

2.3. Chemical Analysis. Biosolids, nonamended soils, and biosolids-amended soils were analyzed (reagents and concentrations are indicated after each of the forms) for various inorganic (water-soluble, distilled water; loosely bound, $1 \mathrm{M}$ $\mathrm{NH}_{4} \mathrm{Cl}$; metal-bound, $1 \mathrm{M} \mathrm{NaOH}$; and calcium-bound, $0.5 \mathrm{M}$ $\mathrm{HCl}$ ) and organic (labile, $0.5 \mathrm{M} \mathrm{NaHCO}_{3}$; moderately labile, $1 \mathrm{M} \mathrm{HCl}$; and nonlabile, ash at $555^{\circ} \mathrm{C}$ ) phosphorus forms using the sequential fractionation procedure. For the watersoluble phosphorus, $0.5 \mathrm{~g}$ of soil sample (dry weight) was placed into a $50 \mathrm{~mL}$ Nalgene centrifuge tube and $25 \mathrm{~mL}$ of distilled water was added. The supernatant was separated from the solid residue by centrifugation, filtered through a $0.22 \mu \mathrm{m}$ filter (paper filter), and analyzed colorimetrically using the ascorbic acid, molybdate method. The residual soil was kept for the next fractionations step, where persulfate digestion for nonlabile phosphorus was replaced by strong acid digestion [27]. The leachate from the columns was analyzed for soluble reactive phosphorus (SRP) according to the procedure described by Kovar and Pierzynski [27] which is an adaptation of the classical ascorbic acid method [28]. In addition, the Olsen phosphorus soil test was determined using $0.5 \mathrm{M} \mathrm{NaHCO}_{3}$ according to the standard procedure [27].

2.4. Modeling P Concentrations. Based on the results of initial soil and biosolids phosphorus analysis, a simple model was created to predict soil phosphorus increases after biosolids application. The expected phosphorus concentrations $\left(c_{f}\right)$ were calculated for each form of phosphorus based upon the initial concentration of each form in the soil $\left(c_{1}\right)$, the 
concentration of each form in the biosolids $\left(c_{b}\right)$, the total mass of soil $\left(M_{s}\right)$, and the quantity of biosolids added $\left(M_{b}\right)$ as follows.

$$
c_{f}=c_{1}+c_{b} * \frac{M_{b}}{M_{s}} .
$$

2.5. Statistical Analysis. A generalized linear mixed model (GLMM) was used to compare the quantities of various forms of phosphorus in biosolids-amended soil versus reference soil, in surface soil versus bottom soil, and over time. Moreover, a GLMM can model response data with non-Gaussian distributions (e.g., exponential, lognormal) and can model a diversity of residuals correlation structures related to the longitudinal variable (e.g., Gaussian, compound symmetry, linear, power, and exponential). General linear mixed model ANOVAs (PROC GLIMMIX, SAS 9.4, SAS Institute, Cary, NC, USA) were used to detect the primary effects of biosolids application and location, as well as the interaction between these factors and time, to determine if concentrations of various forms of $\mathrm{P}$ followed different trajectories in response to treatment (biosolids versus reference) or location (top versus bottom). Such models can be used to fit longitudinal models for data, regardless of whether the response is linear with respect to the longitudinal variable (here, time). GLIMMIX models were run iteratively, with different combinations of specified covariance structure and response variable distributions. The final models were selected on the basis of fit (based upon Akaike Information Criterion (AIC)) and residuals distribution.

\section{Results and Discussion}

The results of the initial soil phosphorus analysis (Figure 1(a)) revealed that the total phosphorus concentration was $0.226 \mathrm{mg} / \mathrm{g}$ of soil. This value is in range with other agriculture soils $(0.050 \mathrm{mg} / \mathrm{g}$ and up to $1.000 \mathrm{mg} / \mathrm{g})$ $[29,30]$. Potentially readily available phosphorus fractions represented by inorganic water-soluble and organic labile fractions were below the detection limit (BDL) of the method which is $0.005 \mathrm{mg} / \mathrm{g}$. This may indicate a significant sorption capacity of the soil, although this was not explicitly measured. Inorganic loosely bound $(0.055 \mathrm{mg} / \mathrm{g}$ of soil $)$ and organic moderately labile fractions $(0.022 \mathrm{mg} / \mathrm{g}$ of soil), however, represent the major part of the bioavailable fractions. They constituted more than $31 \%$ of the total phosphorus concentration in initial soil. This pool of moderately available phosphorus is almost double compared to other studies [31], reinforcing the idea that phosphorus sorption capacity is high for this soil. Relatively unavailable phosphorus fractions, such as inorganic calcium-bound $(0.019 \mathrm{mg} / \mathrm{g}$ of soil) and organic nonlabile $(0.049 \mathrm{mg} / \mathrm{g}$ of soil) fractions, were also minor. Their cumulative contribution to the total phosphorus concentration in initial soil was approximately $13 \%$. The other $43 \%$ of the initial total phosphorus concentration in the soil was represented by the metal-bound phosphorus fraction $(0.115 \mathrm{mg} / \mathrm{g}$ of soil), a fraction that is not directly available for the plants but that can release bioavailable phosphorus under anoxic conditions. The Olsen phosphorus
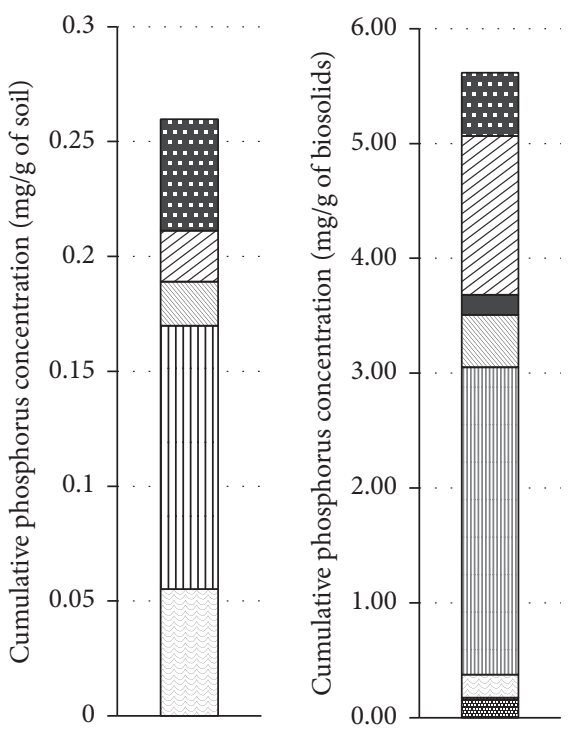

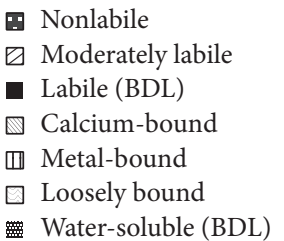

(a)

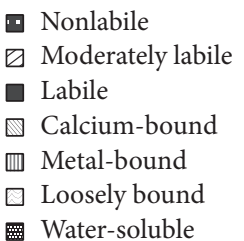

(b)
FIGURE 1: Cumulative initial phosphorus fractions in soil (a) and biosolids (b). Note different concentration scales between the two graphs.

concentration $(0.060 \mathrm{mg} / \mathrm{g})$ suggested that the soil used in the experiment was relatively rich in phosphorus and would be classified as a "no response" soil [32] meaning that the soil is capable of producing high-yielding crops with little or no additional phosphorus fertilizer. However, such soil might increase the potential of phosphorus migration to surrounding water bodies [33].

Biosolids analysis (Figure 1(b)) revealed that the total phosphorus concentration ( $5.617 \mathrm{mg} / \mathrm{g}$ of biosolids) in biosolids was 21 times higher than the total phosphorus concentration in initial soil. Individual phosphorus fractions were also greatly exceeding those in initial soil. This indicates that these biosolids have the potential to fertilize the initial soil. The distribution of the different phosphorus fractions contributed to the total phosphorus concentration, however, was similar to the distribution observed for soil prior to amendment. Such a distribution was unexpected as the organic fractions of phosphorus were expected to be larger (relative to total P) in the biosolids compared to the soil. An advanced level of mineralization of the biosolids may explain the relatively low organic phosphorus content. The cumulative contribution of relatively unavailable phosphorus fractions, such as inorganic calcium-bound $(0.454 \mathrm{mg} / \mathrm{g}$ of biosolids) and organic nonlabile $(0.550 \mathrm{mg} / \mathrm{g}$ of biosolids) fractions, was $17 \%$. The metal-bound phosphorus fraction ( $2.677 \mathrm{mg} / \mathrm{g}$ of biosolids) represented the biggest phosphorus 


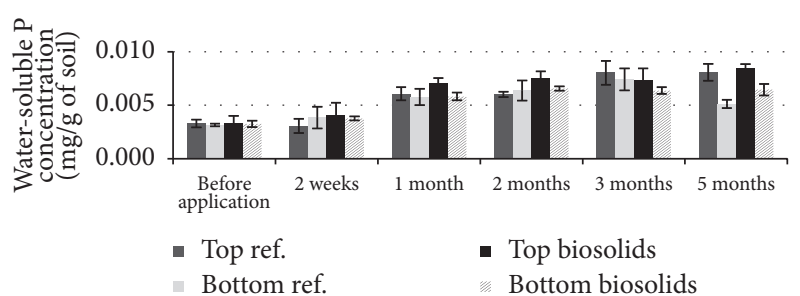

(a)

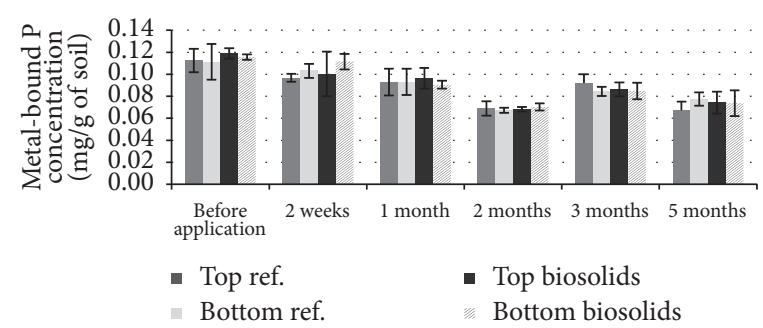

(c)

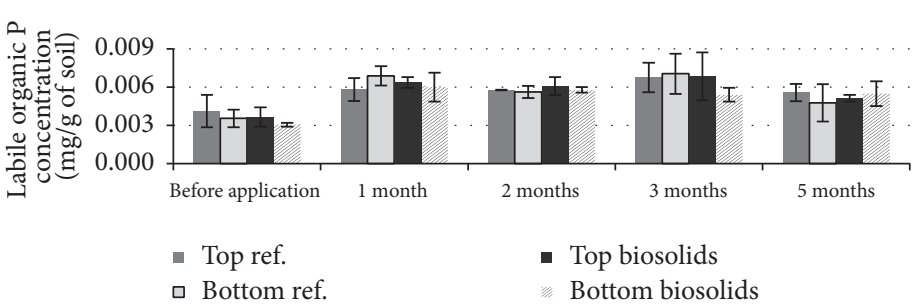

(e)

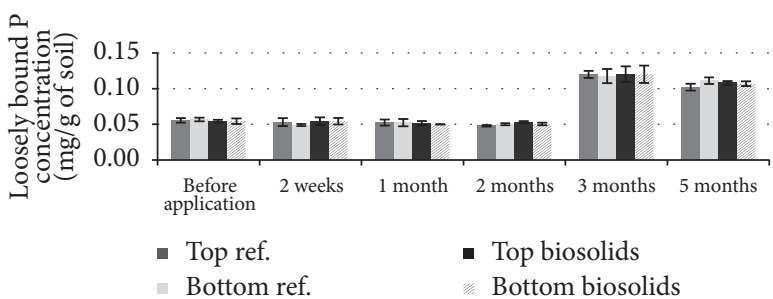

(b)

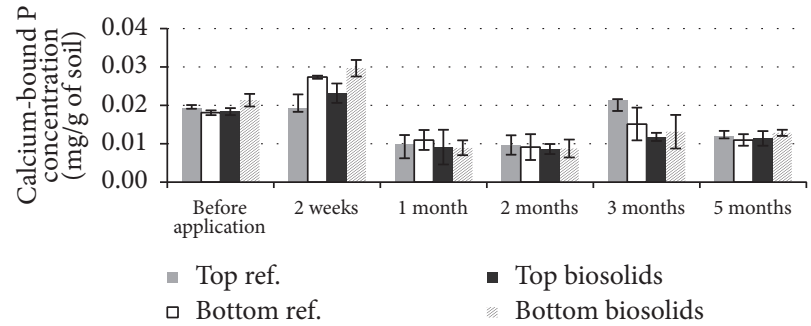

(d)

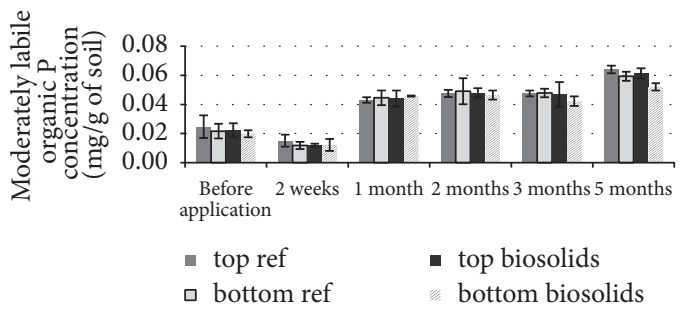

(f)

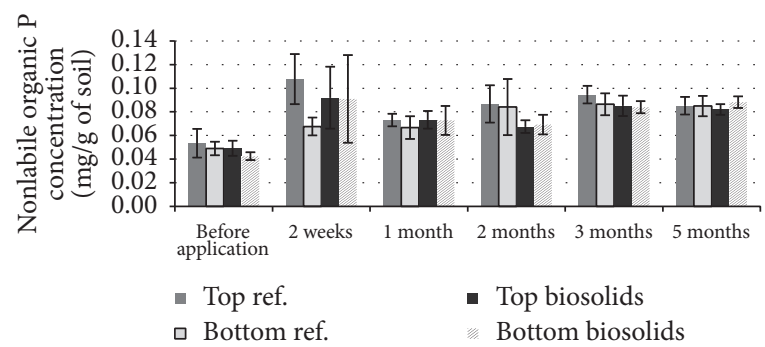

(g)

Figure 2: Phosphorus (P) fractions in soil measured in the reference and biosolids treated soil columns: a) inorganic water-soluble P, b) inorganic loosely bound $\mathrm{P}, \mathrm{c}$ ) inorganic metal-bound $\mathrm{P}, \mathrm{d}$ ) inorganic calcium-bound $\mathrm{P}, \mathrm{e}$ ) organic labile $\mathrm{P}, \mathrm{f}$ ) organic moderately labile $\mathrm{P}$, and g) organic nonlabile P. The error bars represent standard deviation among replicate samples.

pool in biosolids and contributed $47 \%$ to the total phosphorus concentration. High metal-bound phosphorus percentage in biosolids has already been reported by other studies $[34,35]$. This is consistent with the wastewater treatment procedure for phosphorus removal. Readily available watersoluble $(0.174 \mathrm{mg} / \mathrm{g}$ of biosolids), inorganic loosely bound $(0.201 \mathrm{mg} / \mathrm{g}$ of biosolids), and organic labile $(0.175 \mathrm{mg} / \mathrm{g}$ of biosolids) fractions in biosolids represented minor pools of phosphorus. Their cumulative contribution to the total phosphorus concentration was $10 \%$. The greatest difference between biosolids and the soil in the relative contribution to the total phosphorus was found for the moderately labile organic fraction: $1.385 \mathrm{mg} / \mathrm{g}$ of biosolids ( $25 \%$ of total phosphorus) versus $0.022 \mathrm{mg} / \mathrm{g}$ of soil ( $8 \%$ of total phosphorus).
This high value of moderately labile organic fraction was expected as it is relatively common in the biosolids [35].

The results of soil samples analysis after biosolids application are illustrated in Figure 2. When analyzing the statistical significance of changes in phosphorus fractions concentrations, the family of mixed models that consistently resulted in best fit (based on AIC and residuals distribution) were those that fitted a log normal distribution in the response variables ( $P$ pools) and that modeled a compound symmetry residuals covariance structure. All reported statistical results are based upon models of this form (Table 1).

As a general trend, concentrations of all $\mathrm{P}$ fractions varied over time (Table 1). The water-soluble (Figure 2(a)) and the organic labile (Figure 2(e)) phosphorus fractions increased 
TABLE 1: Generalized linear mixed model (GLMM) results for various P pools.

\begin{tabular}{|c|c|c|c|c|c|c|c|}
\hline & \multicolumn{4}{|c|}{ Inorganic $\mathrm{P}$} & \multicolumn{3}{|c|}{ Organic $\mathrm{P}$} \\
\hline & $\begin{array}{l}\text { Water-soluble } \\
\text { P (AIC 48.3) }\end{array}$ & $\begin{array}{l}\text { Loosely bound } \\
\text { P (AIC 24.5) }\end{array}$ & $\begin{array}{l}\text { Metal-bound } \\
\text { P (AIC 42.2) }\end{array}$ & $\begin{array}{l}\text { Calcium-bound } \\
\text { P (AIC 118.5) }\end{array}$ & $\begin{array}{c}\text { Labile P } \\
\text { (AIC 27.7) }\end{array}$ & $\begin{array}{l}\text { Moderately labile } \mathrm{P} \\
\quad \text { (AIC 29.8) }\end{array}$ & $\begin{array}{l}\text { Nonlabile P } \\
\text { (AIC 32.4) }\end{array}$ \\
\hline & \multicolumn{7}{|c|}{$p$-value } \\
\hline $\begin{array}{l}\text { Treatment (biosol. versus } \\
\text { ref.) }\end{array}$ & 0.3213 & 0.8956 & 0.4507 & 0.7984 & 0.5585 & 0.6280 & 0.5083 \\
\hline $\begin{array}{l}\text { Location (top versus } \\
\text { bottom) }\end{array}$ & 0.5762 & 0.7523 & 0.4934 & 0.5819 & 0.3401 & 0.5174 & 0.0551 \\
\hline Time & $<0.0001$ & $<0.0001$ & $<0.0001$ & 0.0017 & $<0.0001$ & $<0.0001$ & $<0.0001$ \\
\hline Time $\times$ treatment & 0.8539 & 0.8745 & 0.5661 & 0.5791 & 0.8268 & 0.9211 & 0.9942 \\
\hline Time $\times$ location & 0.0248 & 0.6792 & 0.8801 & 0.6515 & 0.7214 & 0.8461 & 0.2205 \\
\hline
\end{tabular}

over time, showing some potential for long term phosphorus remobilisation. Although these increases were statistically significant, the maximum amount by which these fractions increased remains very low at less than $0.005 \mathrm{mg} / \mathrm{g}$ of soil (Figure 2(a)).

The loosely bound phosphorus concentrations were constant for the first two months and then increased by $50 \%$ at the three-month period (Figure 2(b)). As the increase in loosely bound phosphorus concentrations was observed for both reference and biosolids-amended soils, it could be explained in part by a $30 \%$ decrease in the metal-bound phosphorus fraction (Figure 2(c)) rather than by biosolids application. The metal-bound phosphorus decreased over time for both treatments in both top and bottom of the soil column. The transformation of the metal-bound phosphorus to the loosely bound phosphorus could have occurred under anoxic conditions inside of the soil columns.

Over a five-month period, the concentration of calciumbound phosphorus decreased by 35\% (Figure 2(d)). The calcium-bound fraction constitutes mainly phosphates from the composition of hydroxyapatite mineral, which makes it a relatively stable fraction [27]. The reduction over time of the calcium-bound fraction is hard to explain, and further investigation may be required. In general, the hydroxyapatite phosphorus constitutes a fraction that leads to an overestimation of phosphorus impact on ecosystems in studies where only the total phosphorus is measured. The dissolution of this form in soil is usually limited to a substantial drop in $\mathrm{pH}$. The sandy loam soil used in the present study has little buffering capacity and as a consequence, accumulation of organic acids may lead to some local dissolution of the hydroxyapatite fraction. The organic moderately labile (Figure 2(f)) and nonlabile (Figure 2(g)) phosphorus concentrations also increased over the five-month period. No explanation for the changes in organic moderately labile and organic nonlabile phosphorus concentrations was found.

One of the main objectives of the present study was to establish in a laboratory setting if biosolids may bring a significant contribution to different phosphorus fractions in agricultural soils. Surprisingly, the chemical analysis of the pools of phosphorus fractions showed that no statistically significant difference was induced by the application of biosolids. No statistically significant difference between biosolids-amended soils and reference soils was observed for any phosphorus pool, nor did changes in phosphorus concentrations over time differ between treatments (time * treatment effect). While some forms of phosphorus did show a time-related change, this was due to chemical and biological processes in the soil and not linked to the application of biosolids. Same trends were observed in both the treated and the reference experimental columns. Therefore, it could be concluded that no measureable increase occurred in any phosphorus fraction as a result of biosolids application (Figure 2). Only water-soluble P differed over time between the top and bottom (time $*$ location effect). While watersoluble $\mathrm{P}$ increased over time in both the top and the bottom of the soil column, the increase was greater in the top portion of the soil than in the deeper soil.

According to the model (Table 2), an increase in almost all phosphorus fractions was expected in the top $5 \mathrm{~cm}$ of the soil columns immediately following biosolids application $(67 \%$ increase for water-soluble, $4 \%$ increase for loosely bound phosphorus, $29 \%$ increase for metal-bound phosphorus, $27 \%$ increase for calcium-bound phosphorus, $60 \%$ increase for organic labile phosphorus, $77 \%$ increase for organic moderately labile phosphorus, and $24 \%$ increase for organic nonlabile phosphorus). However, the expected increase in most pools was near or below the nominal limit of detection for phosphorus analysis. When phosphorus enrichment to the entire column was considered, the relative increase in each fraction was smaller still, with absolute increases below the detection limit for all pools except metal-bound phosphorus. Therefore, this model predicted that application of biosolids with the moderately high total phosphorus concentration, at recommended rates in Ontario, to a fertile soil would result in no measureable increase in phosphorus pools for the integrated soil column, and only marginally discernable increases in the top $5 \mathrm{~cm}$, where the material is most concentrated. The interesting aspect of land applications of biosolids is that despite their relatively large phosphorus concentrations of both bioavailable and unbioavailable forms when compared to the soil concentrations, their impact on the final concentrations in amended soils, due to limits imposed on the application rates, is rather limited. Percentage 
TABLE 2: Quantitative phosphorus concentration increases expected in the entire length of the soil columns within 1 week from biosolids application.

\begin{tabular}{|c|c|c|c|c|c|c|c|}
\hline & \multicolumn{4}{|c|}{ Inorganic fractions } & \multicolumn{3}{|c|}{ Organic fractions } \\
\hline & Water-soluble P & Loosely bound P & Metal-bound P & $\begin{array}{c}\text { Calcium-bound } \\
\mathrm{P} \\
\end{array}$ & Labile P & Moderately labile P & $\begin{array}{c}\text { Nonlabile } \\
\text { P }\end{array}$ \\
\hline $\begin{array}{l}\text { Expected increase } \\
\text { in P fractions (\%) }\end{array}$ & & & & & & & \\
\hline Top $5 \mathrm{~cm}$ & 67.0 & 4.5 & 28.7 & 26.5 & 59.9 & 76.8 & 23.5 \\
\hline $\begin{array}{l}\text { Expected increase } \\
\text { in P fractions (\%) }\end{array}$ & & & & & & & \\
\hline Entire column & 8.4 & 0.6 & 3.6 & 3.3 & 7.5 & 9.6 & 2.9 \\
\hline
\end{tabular}

change calculations from biosolids concentrations, soil concentrations, and application rates translate to relatively small increases in the nominal concentrations of the phosphorus forms in the soil. The detection limit allows accurate measurement of $\geq 0.1 \mathrm{mg} \mathrm{P} / \mathrm{kg}$ soil. The changes in concentration are below this value, so soil phosphorus remained virtually unaffected after biosolids application.

The experimental design accounted for both temporal changes and potential vertical migration of the phosphorus in the soil columns. The narrow diameter of the columns was meant to avoid lateral escapes of the phosphorus, limiting the potential migration of the phosphorus fractions to the vertical direction. The data obtained from the upper layer and from a depth of $35 \mathrm{~cm}$ in the columns showed no difference for any phosphorus fraction between the treated and untreated soils. This suggests that the vertical transport of phosphorus remained insignificant for the duration of the experiment, regardless of the phosphorus fraction considered. As mentioned, changes in concentrations of $\mathrm{P}$ at the top of the column were low to statistically insignificant. The possible migration of these nutrients towards the lower region of the column did not occur in the case of this study. Soil adsorption and biological fixation are both mechanisms that could explain this lack of mobility.

The soil and biosolids used in this experiment represented a kind of worst-case scenario, that is, phosphorusrich anaerobically digested biosolids applied to soil that was also phosphorus-rich, providing conditions under which the phosphorus might be expected to migrate through the soil towards the drainage system rather than being immobilized [33]. This was not observed. Accordingly, it is unlikely that phosphorus vertical migration would be observed following application to more phosphorus-poor soils with higher adsorption capacity for phosphorus, or in soils receiving biosolids produced by further processing such as alkaline stabilization or drying which may decrease phosphorus mobility.

In order to account for the phosphorus movement in the soil columns, the laboratory-based experimental setup allowed the collection of water percolating down through the soil. These leachate samples collected from both biosolidsamended and reference soil columns were analyzed for soluble reactive phosphorus.

The concentrations of soluble reactive phosphorus in leachate samples collected from biosolids-amended soil columns were noted to be very close to the concentrations of soluble reactive phosphorus in leachate samples collected from reference soil columns (Figure 3). No significant difference was observed between samples ( $t_{46}=0.31, p=0.758$ ). The absence of a significant difference in phosphorus concentrations between leachate from biosolids-amended columns and leachate from reference columns is in accord with the lack of statistical difference between the concentrations of various forms of phosphorus in biosolids-amended columns and reference columns (Figure 2). Within the five months of the research, leachate from both biosolids-amended soil columns and reference soil columns demonstrated phosphorus concentrations around $0.039-0.054 \mathrm{mg} / \mathrm{L}$. These concentrations were much smaller than the concentrations of phosphorus measured in runoff from biosolids-amended soils [17, 20, 29, 36-38]. but still exceeded concentrations suggested as optimal for limiting eutrophication potential (below $0.025 \mathrm{mg} / \mathrm{L}$ in streams and $0.01 \mathrm{mg} / \mathrm{L}$ in lakes) [39]. Horizontal migration of $\mathrm{P}$ in runoff and erosion soon after land application would seem to be a much more important route of potential loading to surface water than vertical transport and groundwater transfers.

\section{Conclusions}

The results of the soil analysis revealed that concentrations of several phosphorus fractions changed significantly over time. The water-soluble, the organic labile phosphorus, and the loosely bound phosphorus concentrations increased during the five months of the experiment. However, this increase was observed for both reference and biosolids-amended soils and can be linked to a decrease in the metal-bound phosphorus fraction which could have occurred under anoxic conditions inside of the soil columns.

No statistically significant difference between biosolidsamended soils and reference soils was observed for any phosphorus pool, nor did changes in phosphorus concentrations over time differ between treatments (time $*$ treatment effect). Therefore, it can be concluded that no measureable increase occurred in any phosphorus fraction as a result of biosolids application. Thus, phosphorus from the biosolids-amended surface does not measurably migrate through the soil profile towards underground tile drainage systems under the conditions simulated within the current research. This was confirmed by the lack of significant difference between 


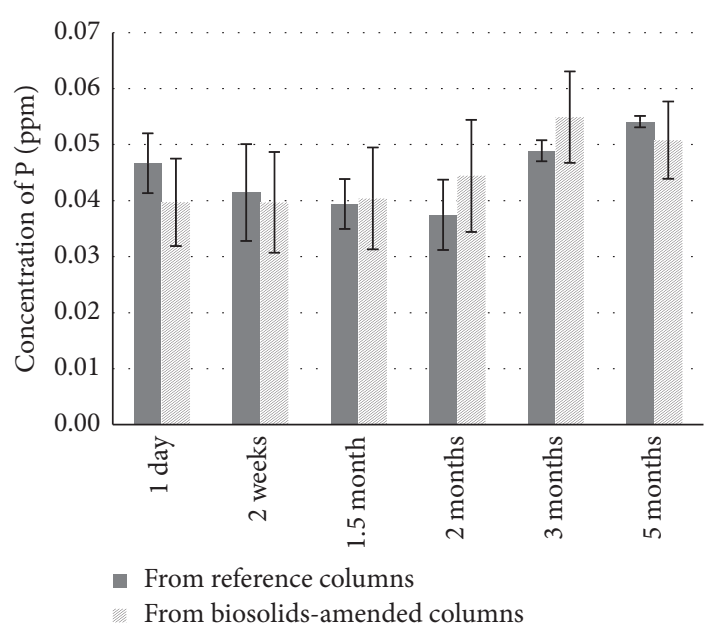

FIgURE 3: Concentrations of soluble reactive phosphorus in analyzed leachate. The error bars represent standard deviation among replicate samples.

concentrations of soluble reactive phosphorus in the leachate from various columns.

The current study provided laboratory-based evidence that anaerobically digested biosolids with phosphorus concentration of $5.6 \mathrm{mg} / \mathrm{g}$ of biosolids or below, when applied at the rate of 8 dry tons (dry weight) ha ${ }^{-1}$ to sandy loam soils with no or minimal slope, do not increase $\mathrm{P}$ leaching.

\section{Additional Points}

Core Ideas. We examined the impact of biosolids on soil phosphorus fractions in vertical profiles. Concentrations of several phosphorus fractions changed significantly over time. Mobile phosphorus fractions increased during the five months of the experiment. No difference between biosolids-amended and reference soils was observed. In specific conditions, biosolids can be applied without risk of increased P leaching.

\section{Competing Interests}

The authors declare that they have no competing interests.

\section{Acknowledgments}

This paper was possible due to the financial support provided by the Environmental Applied Science and Management graduate program from the Yeates School of Graduate Studies (YSGS) at Ryerson University.

\section{References}

[1] EPA, Land Application of Biosolids: Process Design Manual, Taylor \& Francis, 1997.

[2] A. Atalay, C. Bronick, S. Pao et al., "Nutrient and microbial dynamics in biosolids amended soils following rainfall simulation," Soil and Sediment Contamination, vol. 16, no. 2, pp. 209219, 2007.
[3] A. L. Shober and J. T. Sims, "Phosphorus restrictions for land application of biosolids: current status and future trends," Journal of Environmental Quality, vol. 32, no. 6, pp. 1955-1964, 2003.

[4] O. Oenema and C. W. J. Roest, "Nitrogen and phosphorus losses from agriculture into surface waters; the effects of policies and measures in the Netherlands," Water Science and Technology, vol. 37, no. 3, pp. 19-30, 1998.

[5] T. C. Daniel, A. N. Sharpley, and J. L. Lemunyon, "Agricultural phosphorus and eutrophication: a symposium overview," Journal of Environmental Quality, vol. 27, no. 2, pp. 251-257, 1998.

[6] B. Li and M. T. Brett, "The impact of alum based advanced nutrient removal processes on phosphorus bioavailability," Water Research, vol. 46, no. 3, pp. 837-844, 2012.

[7] V. Smil, "Phosphorus in the environment: natural flows and human interferences," Annual Review of Energy and the Environment, vol. 25, pp. 53-88, 2000.

[8] K. A. Anderson and J. A. Downing, "Dry and wet atmospheric deposition of nitrogen, phosphorus and silicon in an agricultural region," Water, Air, and Soil Pollution, vol. 176, no. 1-4, pp. 351-374, 2006.

[9] J. J. Hanway and J. M. Laflen, "Plant nutrient losses from tile outlet terraces," Journal of Environmental Quality, vol. 3, no. 4, pp. 351-356, 1974.

[10] G. W. Randall, T. K. Iragavarapu, and M. A. Schmitt, "Nutrient losses in subsurface drainage water from dairy manure and urea applied for corn," Journal of Environmental Quality, vol. 29, no. 4, pp. 1244-1252, 2000.

[11] R. Gächter, J. M. Ngatiah, and C. Stamm, "Transport of phosphate from soil to surface waters by preferential flow," Environmental Science \& Technology, vol. 32, no. 13, pp. 1865$1869,1998$.

[12] D. W. Lucero, D. C. Martens, J. R. McKenna, and D. E. Starner, "Accumulation and movement of phosphorus from poultry litter application on a Starr clay loam," Communications in Soil Science and Plant Analysis, vol. 26, no. 11-12, pp. 1709-1718, 1995.

[13] J. Magid, M. B. Jensen, T. Mueller, and H. C. B. Hansen, "Phosphate leaching responses from unperturbed, anaerobic, or cattle manured mesotrophic sandy loam soils," Journal of Environmental Quality, vol. 28, no. 6, pp. 1796-1803, 1999.

[14] K. C. Makris, J. H. Grove, and C. J. Matocha, "Colloidmediated vertical phosphorus transport in a waste-amended soil," Geoderma, vol. 136, no. 1-2, pp. 174-183, 2006.

[15] J. T. Sims, R. R. Simard, and B. C. Joern, "Phosphorus loss in agricultural drainage: historical perspective and current research," Journal of Environmental Quality, vol. 27, no. 2, pp. 277-293, 1998.

[16] B. L. Turner and P. M. Haygarth, "Phosphorus forms and concentrations in leachate under four grassland soil types," Soil Science Society of America Journal, vol. 64, no. 3, pp. 1090-1099, 2000.

[17] A. Hanief, D. Matiichine, A. E. Laursen, I. Vadim Bostan, and L. H. McCarthy, "Nitrogen and phosphorus loss potential from biosolids-amended soils and biotic response in the receiving water," Journal of Environmental Quality, vol. 44, no. 4, pp. 12931303, 2015.

[18] H. A. Elliott, R. C. Brandt, and G. A. O'Connor, "Runoff phosphorus losses from surface-applied biosolids," Journal of Environmental Quality, vol. 34, no. 5, pp. 1632-1639, 2005.

[19] C. J. Penn and J. T. Sims, "Phosphorus forms in biosolidsamended soils and losses in runoff: effects of wastewater 
treatment process," Journal of Environmental Quality, vol. 31, no. 4, pp. 1349-1361, 2002.

[20] R. Quilbé, C. Serreau, S. Wicherek, C. Bernard, Y. Thomas, and J.-P. Oudinet, "Nutrient transfer by runoff from sewage sludge amended soil under simulated rainfall," Environmental Monitoring and Assessment, vol. 100, no. 1-3, pp. 177-190, 2005.

[21] N. C. Hansen, T. C. Daniel, A. N. Sharpley, and J. L. Lemunyon, "The fate and transport of phosphorus in agricultural systems," Journal of Soil and Water Conservation, vol. 57, no. 6, pp. 408417, 2002.

[22] W. G. Harris, R. D. Rhue, G. Kidder, R. B. Brown, and R. Littell, "Phosphorus retention as related to morphology of sandy coastal plain soil materials," Soil Science Society of America Journal, vol. 60, no. 5, pp. 1513-1521, 1996.

[23] A. E. Hartemink, "Encyclopedia of soils in the environment (4 volumes), D. Hillel, J.L. Hatfield, D.S. Powlson, C. Rosenzweig, K.M. Scow, M.J. Singer, D.L. Sparks (Eds.), 2005, ISBN 0-12348530-4, Elsevier Academic Press, Amsterdam, Hardbound, 2119 pp., US\$1,095," Encyclopedia of Soils in the Environment, vol. 132, no. 1-2, pp. 240-246, 2006.

[24] Y. Markunas, Vertical phosphorus migration in biosolidsamended soils: concentrations in soils and leachates [Ph.D. thesis], Ryerson University, Toronto, Canada, 2014.

[25] Ministry of Environment and Energy, Ministry of Agriculture, Food, and Rural Affairs, Guidelines for the Utilization of Biosolids and Other Wastes on Agricultural Land, Ministry of Environment and Energy, Ministry of Agriculture, Food and Rural Affairs, Toronto, Canada, 1996.

[26] N. Gottschall, M. Edwards, E. Topp et al., "Nitrogen, phosphorus, and bacteria tile and groundwater quality following direct injection of dewatered municipal biosolids into soil," Journal of Environmental Quality, vol. 38, no. 3, pp. 1066-1075, 2009.

[27] J. Kovar and G. Pierzynski, Methods of Phosphorus Analysis for Soils, Sediments, Residuals, and Waters, Virginia Tech University, Blacksburg, Va, USA, 2nd edition, 2009.

[28] J. Murphy and J. P. Riley, "A modified single solution method for the determination of phosphate in natural waters," Analytica Chimica Acta, vol. 27, no. C, pp. 31-36, 1962.

[29] T. W. Andraski and L. G. Bundy, "Relationships between phosphorus levels in soil and in runoff from corn production systems," Journal of Environmental Quality, vol. 32, no. 1, pp. 310-316, 2003.

[30] J. Liu, H. Aronsson, L. Bergström, and A. Sharpley, "Phosphorus leaching from loamy sand and clay loam topsoils after application of pig slurry," SpringerPlus, vol. 1, no. 1, article 53, pp. 1-10, 2012.

[31] P. P. Motavalli and R. J. Miles, "Soil phosphorus fractions after 111 years of animal manure and fertilizer applications," Biology and Fertility of Soils, vol. 36, no. 1, pp. 35-42, 2002.

[32] OMAFRA, Macro and Secondary Nutrients-Soil Diagnostics, Edited by Q. S. P. F. Ontario, Soil Diagnostics, Government of Ontario, 2009.

[33] J. Legg, Topsoil Report Ranges, Agri-Food Laboratories, Guelph, Canada, 2013.

[34] Z. He, H. Zhang, G. S. Toor et al., "Phosphorus distribution in sequentially extracted fractions of biosolids, poultry litter, and granulated products," Soil Science, vol. 175, no. 4, pp. 154-161, 2010 .

[35] X.-L. Huang, Y. Chen, and M. Shenker, "Chemical fractionation of phosphorus in stabilized biosolids," Journal of Environmental Quality, vol. 37, no. 5, pp. 1949-1958, 2008.
[36] F. R. Cox and S. E. Hendricks, "Soil test phosphorus and clay content effects on runoff water quality," Journal of Environmental Quality, vol. 29, no. 5, pp. 1582-1586, 2000.

[37] A. N. Sharpley, W. W. Troeger, and S. J. Smith, "Water quality: the measurement of bioavailable phosphorus in agricultural runoff," Journal of Environmental Quality, vol. 20, no. 1, pp. 235238, 1991.

[38] J. W. White, F. J. Coale, J. T. Sims, and A. L. Shober, "Phosphorus runoff from waste water treatment biosolids and poultry litter applied to agricultural soils," Journal of Environmental Quality, vol. 39, no. 1, pp. 314-323, 2010.

[39] V. H. Smith, G. D. Tilman, and J. C. Nekola, "Eutrophication: impacts of excess nutrient inputs on freshwater, marine, and terrestrial ecosystems," Environmental Pollution, vol. 100, no. 13, pp. 179-196, 1998. 

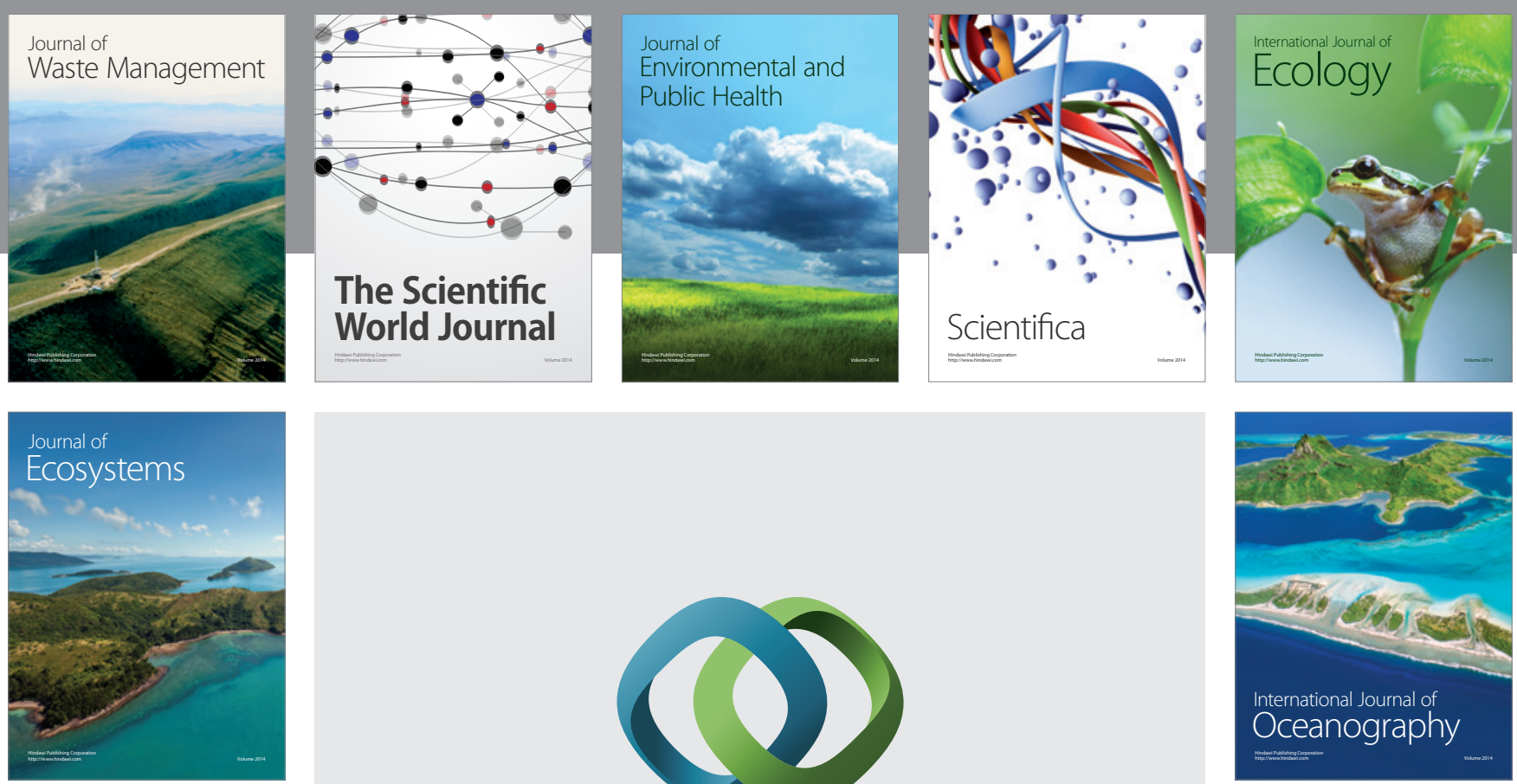

The Scientific World Journal
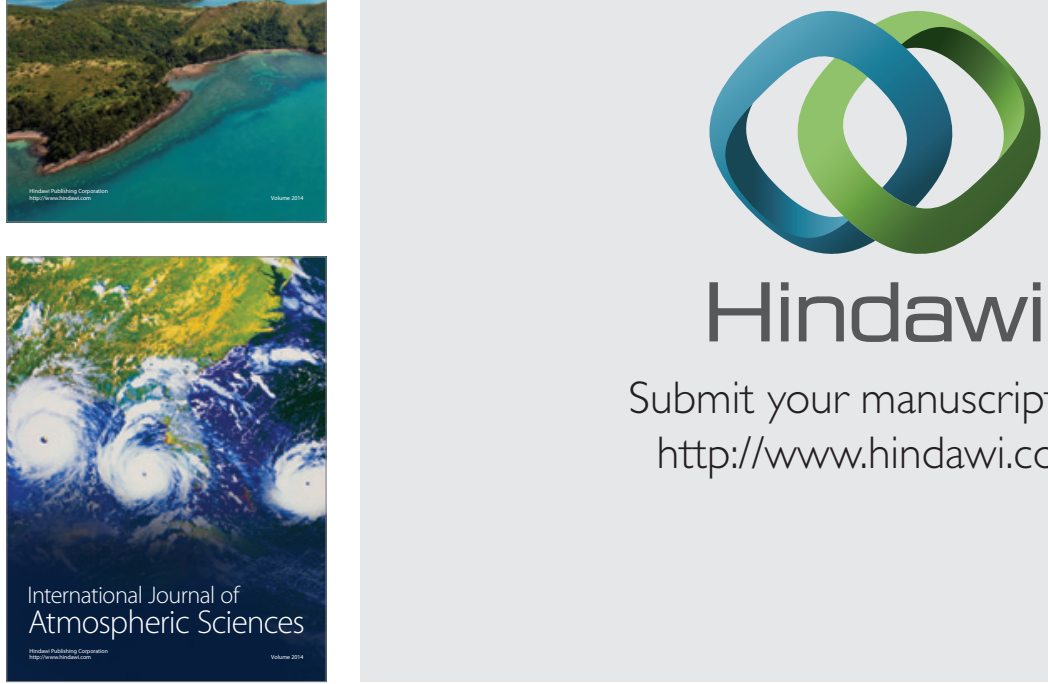

\section{Hindawi}

Submit your manuscripts at

http://www.hindawi.com
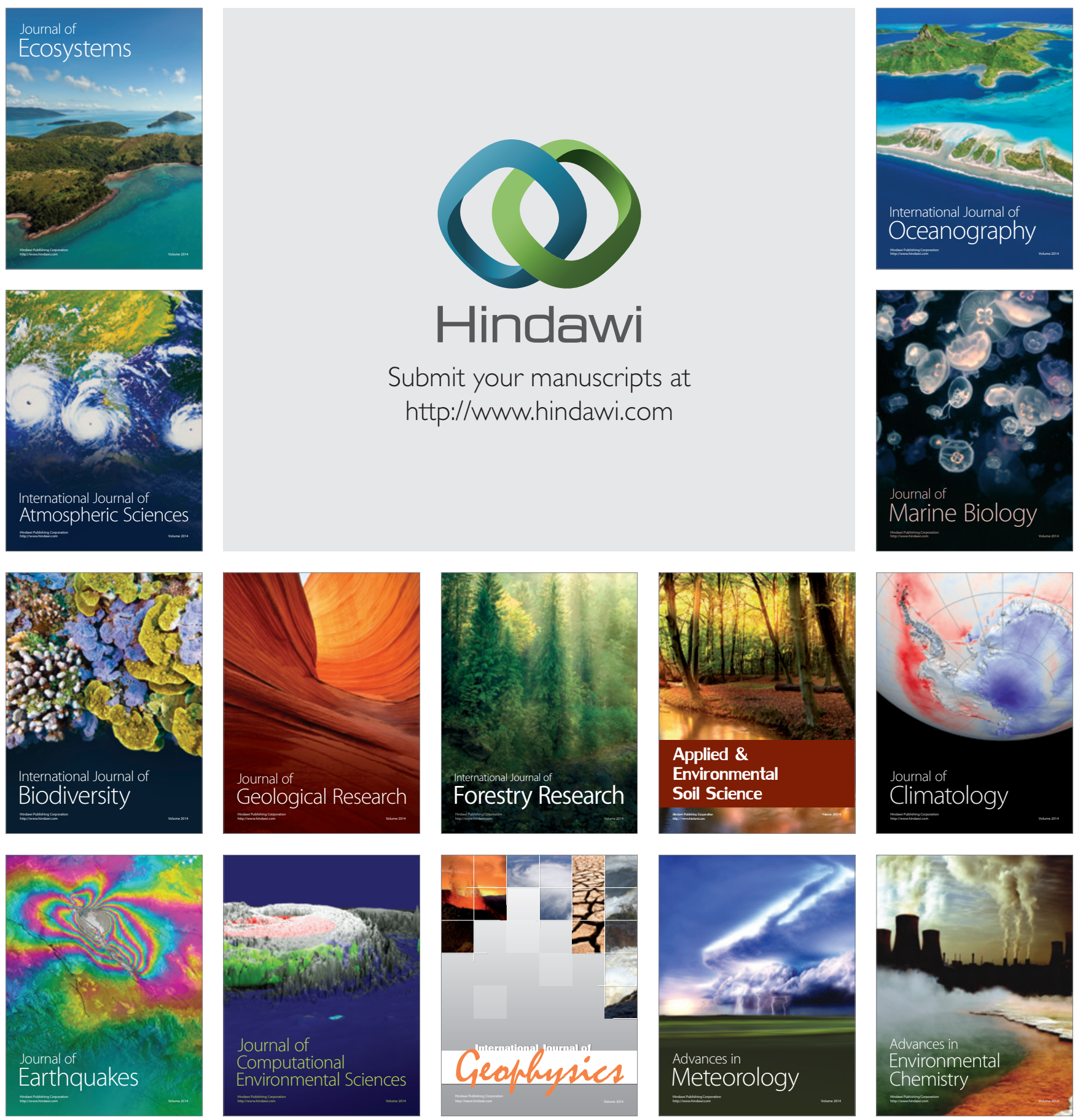